\title{
LITERATURA NO SINGULAR/LITERATURA NO PLURAL NOTAS SOBRE O LIVRO Ó FALA QUE FOSTE FALA
}

\author{
Maria Isaura Rodrigues Pinto (UERJ) \\ $\underline{\text { m.isaura@ig.com.br }}$
}

O lançamento de Ó fala que foste fala nos apresenta a produção poética de Joaquim Espadinha. As décimas reunidas correspondem à atividade do poeta no final do século XIX e na primeira metade do século XX, mas a organizadora da obra, a professora doutora Maria da Conceição Espadinha Ruivo, neta do poeta, esclarece, no prefácio, tratar-se apenas de uma fração, visto que muitas décimas ficaram perdidas.

Como atesta a recolha de poemas feita por investigadores do projeto pioneiro, no qual me incluo, "Novas poéticas de resistência: o século XXI", dirigido pela professora doutora Graça Capinha, através de missões realizadas pelo pais, a décima é, à parte de uma ou outra variante, o texto em versos mais difundido entre o povo, no sul de Portugal. Provavelmente, por essa razão, fatia significativa da poesia popular, que vem sendo editada pelas câmaras municipais dessa região e também por poetas, em edições autônomas, enquadra-se nesse tipo de produção, cuja forma composicional estrutura-se num conjunto regular de quatro estrofes de dez versos, glosando uma quadra (mote).

Não falta quem coloque essa composição poética na mesma linha da literatura de cordel do Brasil. Os pesquisadores Virgílio López Lemus e Maximiano Trapero, citados por Paulo Lima, no livro $O$ fado operário no Alentejo, são pioneiros na tentativa de elaborar uma cartografia extensiva de regiões, na Ibero-América, ocupadas pela décima. Eles destacam, em seus estudos, reconhecidos como contributo importante para o entendimento desse modo de fazer poesia, sete zonas. A última zona corresponde à do Nordeste brasileiro, onde a décima, caracterizando-se pela cantoria (repente) e associando-se ao

\footnotetext{
${ }^{30}$ Esta pesquisa decorre no âmbito do projeto "Novas Poéticas de Resistência: o século XXI em Portugal", um projeto financiado pela Fundação para a Ciência e Tecnologia (FCT), com a referência FCOMP-01-0124-FEDER-007264, coordenado pela professora doutora Graça Capinha, a ser desenvolvido no Centro de Estudos Sociais da Universidade de Coimbra.
} 
cordel, ganha feição própria. Os autores veem uma ligação entre o sul de Portugal e a zona do Nordeste e aludem à possibilidade de que a décima tenha se implantado na região sul de Portugal e aí conquistado espaço no gosto popular devido a processos de "torna-viagem" (Apud LIMA, 2004, p. 34).

Um dado importante a considerar na constituição da décima é o fato de que nela se apreende o que é próprio da organização do pensamento oral (ONG, 1998), em que estruturas formulares relacionadas a padrões sonoros e rítmicos de versificação geram musicalidade, funcionando como recurso de aparelhamento da memória. Inscritas no âmbito das produções poéticas que remontam às transmissões orais, as décimas do poeta Joaquim Espadinha, orientando-se por processos orais do pensamento, retêm como elementos de destaque da sua construção formular o tom agonístico da contenda verbal improvisada e a expressão acentuada do elogio, fundada na antiga oralidade heroica (ONG, 1998, p. 55).

Nesse sentido, o livro, escrito do ponto de vista da experiência, mas exibindo acentuado engenho no nível da transfiguração imaginativa, o que o impede de resvalar para a gratuidade retratista, ganha, por exemplo, na sua segunda parte (formada por "Quem te havia de dizer Alfundão" e pelas décimas em que as vozes femininas das três principais ruas da aldeia, personificadas, travam uma disputa verbal, singelamente encerrada pela fala da rua do poeta, a Rua do Cotovelo), um ar de naturalidade e improviso especiais, de modo que o texto impresso, mergulhado no conhecimento da vida cotidiana da freguesia aí enaltecida, possa ser imaginado como uma produção oral sendo dita/cantada em voz alta na presença de ouvintes, em praça pública.

Vale a pena observar, nesse sentido, a seguinte estrofe da décima referente à Rua do Cotovelo, onde se exalta, entre outros fatores, o Largo da Praça, que se torna a praça de touros, em dias de festa:

Não sou bem assituada

Mas estou cheia de brio

Não tem conta em mim o gentio

Quando há uma tourada

Toca a filarmônica de assentada

E assim posso dizê-lo

E vê-se todo o modelo 
Quanto haja em trajar

Então quero-lhe ganhar

Eu Rua do Cotovelo (p. 49).

A inclinação da obra para o antigo mundo oral faz com que as décimas do autor se ocupem, mais especificamente, de ouvintes e não de leitores, o que fica patente com o emprego de palavras e expressões que se referem à "voz viva". Oferece exemplo disso o uso do verbo dizer, na estrofe anteriormente citada. Ao longo da obra, é tal a perícia com que é manejado o instrumental poético na busca da voz, que o leitor, remetido à modalidade vocal-auditiva da comunicação, se sente dela participante.

Atenta à dimensão oral do fazer poético de Joaquim Espadinha que, integrado com o canto, atualiza de maneira eficiente, em vários momentos, o estilo inconfundível do despique, Maria da Conceição vai retirar o título da obra do mote de uma das décimas do poeta, em que, por duas vezes, se emprega a palavra "fala" e da qual só restaram fragmentos. Dessa forma, indica, de antemão, ser a instância da voz o cerne da matéria poética.

A poesia do autor, articulada com o código da fala, chega ao livro como forma de preservar um "corpus" de décimas que teve, primeiramente, o suporte da escrita manual e que encontra, agora, no recurso das tecnologias de impressão, um modo de garantir a sua permanência e promover a sua divulgação. O livro, cuidadosamente composto, contém inúmeras fotos e reproduções de materiais diversos, que ajudam na reconstituição da trajetória de vida do poeta. Nele sobressai, além disso, o agrupamento das décimas em cinco blocos; cada um deles precedido de um comentário consistente que traz contribuições de grande utilidade para a compreensão da obra.

Em termos gerais, na primeira parte, as décimas da juventude do poeta denunciam infortúnios do povo em anos de secas intensas e revelam posicionamentos políticos. Na segunda, a poesia assume, mais especificamente, um tom de crônica da terra. Com traços de humor, na terceira, são dados a conhecer, poeticamente, episódios do cotidiano. O tom humorístico se desloca para o âmbito do privado, na quarta parte. Já na última, emerge uma escrita sombria e melancólica que, por fim, volta a dar lugar, na última décima "Amigos quando eu morrer", ao humor e à brincadeira. 
Maria da Conceição, mais do que frisar o valor artístico da produção do poeta Joaquim Espadinha, acentua, em suas observações, que o livro "é também um tributo ao talento do artista popular, conhecido por poucos e facilmente esquecido, porque as oportunidades não são iguais para todos" (p. 8). Ao comentar a obra, a organizadora faz questão de deixar ver que (re)conhece e valoriza uma outra forma de fazer poesia para além da institucionalizada, a qual admite não ser atribuída igual importância e oportunidade de difusão. Para Paulo Lima, "Todos estes poetas populares são fotografias pobres de uma outra poesia, a culta ou erudita, sendo por isso que se realça tanto o facto de serem analfabetos e a pobreza que arrastam" (2004, p. 103). Teorizando mais direta e amplamente sobre o descrédito dirigido a essa "outra" literatura, assim se pronuncia Arnaldo Saraiva, em Literatura marginalizada: "A literatura dita popular, antiga ou recente, tem sido a maior vítima dos muitos e vários censores que têm existido ao longo da sua história - e que obviamente não desapareceram com o 25 de Abril" (1975, p. 106).

São inúmeros e de ordem variada os fatores responsáveis pela função repressora da cultura hegemônica (a propósito, é ainda Arnaldo Saraiva que adverte: "não se pense que isso é apenas um problema político, porque é também um problema científico e um problema estético" (1975, p. 113), mas um deles, com efeito, tem existência especialmente atuante: trata-se do preconceito em relação à linguagem da literatura "popular" que, mesmo impressa, possui caráter oral e frequentemente distanciado da norma linguística socialmente prestigiada.

Sobre a questão do preconceito linguístico, são bastante oportunas as seguintes colocações feitas por Michel de Certeau, no livro A cultura no plural, ao referir-se à ilusão da existência de uma unidade linguística, sustentada por intelectuais franceses, já que essa visão também se aplica à língua portuguesa:

$\mathrm{O}$ francês do mestre parece sempre visar à preservação do fetiche de uma língua unitária, passadista e chauvinista, a dos autores "aceitos", a de uma categoria social, a de uma região privilegiada. Essa língua dos mestres nega a realidade. [...] A salvaguarda da "pureza" prevalece sobre a preocupação com o intercâmbio (2008, p. 124).

Um exemplo significativo de como a literatura popular envolve aspectos próprios da crença na ideia ingênua da existência de uma 
unidade linguística, associada à pureza da língua, é a ação corretiva muito frequente, que é imposta à linguagem do poeta popular no momento da fixação dos textos para edição da obra. Esse procedimento mostra que, mesmo quando o objetivo é promover as produções populares como formas não canônicas de expressão literária, ampliando-lhes o circuito de leitura, o vínculo com uma homogeneidade de meio e de classe intelectual atua e, não permitindo vigorar plenamente o "plural", leva a uma inserção equivocada na linha de uma conduta elitista e excludente em relação à linguagem, que, quer se queira ou não, atua como mecanismo de censura (Cf. PINTO, 2006, p. 21).

Em Ó fala que foste fala, as décimas do poeta têm a ortografia modernizada e os "erros evidentes" corrigidos, como informa, no prefácio, a organizadora. Mas, ela própria esclarece, logo a seguir, dando um sinal positivo ao procedimento, que o critério usado para fixação do texto, mesmo com a intervenção feita, deixou "intocada a forma original em todas as suas características populares, consubstanciais a este modo específico de expressão poética" (p. 24). O que se pode observar é que houve uma minimização da atitude corretiva ((in)dispensável?), que, basicamente, se reduziu a aspectos ortográficos. Assim, a organizadora, ao optar pela intocabilidade da forma original - repositório de um saber das camadas populares, apresentado como legítimo -, empenhou-se em assegurar a vigência do "plural" com a não ocultação das diferenças pela hegemonia do discurso dominante, cuja lógica, derivada da "monocultura do saber e do rigor do saber" (SOUSA SANTOS, 2002, p. 247), consiste em impor a sua retórica de classe como critério exclusivo de qualidade das manifestações literárias.

\section{REFERÊNCIAS BIBLIOGRÁFICAS}

CERTEAU, Michel de. A cultura no plural. Campinas: Papirus, 2008.

LIMA, Paulo. O fado operário no Alentejo, séculos XIX/XX: O contexto do profanista Manuel José Santinhos. Vila Verde: Tradisom, 2004.

ONG, Walter. Oralidade e cultura escrita. Campinas: Papirus, 1998. 


\section{FACULDADE de FoRMAÇÃO de PROFESSORES}

PINTO, Maria Isaura Rodrigues. O cordel como objeto de ensino. Linguagem em (Re)vista, $\mathrm{n}^{\circ}$ 5, 2006, p. 21-28.

RUIVO, Maria da Conceição Espadinha. Ó fala que foste fala: Décimas de Joaquim Espadinha. Porto: Edições Afrontamento, 2009.

SARAIVA Arnaldo. Literatura marginalizada. Porto: Edições Árvore, 1975.

SOUZA SANTOS, Boaventura de. Para uma sociologia das ausências e uma sociologia das emergências. Revista Crítica de Ciências Sociais, $\mathrm{n}^{\mathrm{o}}$ 63, 2002, pp. 237-280. 